\title{
Pretreatment of Loblolly Pine Tree Needles Using Deep Eutectic Solvents
}

\author{
Prathima Gujjula, Narendra Kumar and Joan G. Lynam * D \\ Department of Chemical Engineering, Louisiana Tech University, P.O. Box 10348, 600 Dan Reneau Drive, \\ Ruston, LA 71272, USA; gujjulaprathima@gmail.com (P.G.); nku004@latech.edu (N.K.) \\ * Correspondence: lynam@latech.edu; Tel.: +1-(318)-257-3124
}

Citation: Gujjula, P.; Kumar, N.; Lynam, J.G. Pretreatment of Loblolly Pine Tree Needles Using Deep Eutectic Solvents. Biomass 2021, 1 , 1-10. https://doi.org/10.3390/ biomass1010001

Academic Editor: S David Jackson

Received: 14 April 2021

Accepted: 19 May 2021

Published: 1 June 2021

Publisher's Note: MDPI stays neutral with regard to jurisdictional claims in published maps and institutional affiliations.

Copyright: (c) 2021 by the authors. Licensee MDPI, Basel, Switzerland. This article is an open access article distributed under the terms and conditions of the Creative Commons Attribution (CC BY) license (https:// creativecommons.org/licenses/by/ $4.0 /)$.

\begin{abstract}
Deep eutectic solvents (DES) are new 'green' solvents that have a high potential for biomass processing because of their low cost, low toxicity, biodegradability, and easy recycling. When Loblolly pine trees are harvested, their branches with needles are typically left in brush piles and decompose very slowly. Exploring the effect of DES pretreatment on waste pine needles was the goal of the present work. Loblolly pine needles were treated with three types of DES to prepare the biomass for enzymatic hydrolysis to glucose, a subject not readily found in the literature. The resulting products were analyzed by Fourier transform infrared spectroscopy, fiber analysis, and high-performance liquid chromatography. Glucose yields after pretreatment and hydrolysis were found to be six times that for untreated biomass with two of the DES. Fiber analysis indicated removal of lignin, hemicellulose, and ash from the needle biomass. Enhanced glucose yield was due to removal of lignin and disruption of biomass structure during pretreatment, so that the pretreated biomass was rich in cellulosic content. Based on the results shown in this study, among the three types of DES, formic acid:choline chloride and acetic acid:choline chloride pretreatment had better potential for biomass pretreatment compared to lactic acid:choline chloride.
\end{abstract}

Keywords: pine needles; biomass; mass yield; enzymatic hydrolysis; glucose yield; FTIR

\section{Introduction}

Environmentally sustainable sources that provide tangible fuels and materials rather than electricity are needed in the world economy. Comprised of biopolymers of cellulose, hemicellulose, and lignin, lignocellulosic biomass have the potential to be such a resource [1]. Production of biofuels is feasible by fermenting cellulose and hemicellulose (polysaccharides) into ethanol or butanol, provided that an optimized pretreatment of the biomass to separate out lignin has occurred [2]. Biofuels made from biomass provides unique environmental and economic strategic benefits, and it can be considered a safe and clean liquid fuel alternative to fossil fuels [3]. Nevertheless, the biomass must be subjected to pretreatment processes to liberate the sugars needed for fermentation. Lignin removed by pretreatment can also be used for various industrial and biomedical applications, including biofuels, chemicals and polymers, and the development of nanomaterials for drug delivery [4].

Loblolly pine (Pinus taeda), also known as southern yellow pine, has a rapid growth rate and is one of the most abundant species in the United States [5]. It has significant commercial importance in the pulp and paper industry, as well as for construction. When harvested, branches with their needles are typically left in brush piles, while the tree trunks are transported for use. The needles are thus left as a waste product. The needles have a significantly different structure and lignin content compared to the wood and do not readily compost into the soil [6]. If these needles were harvested, they could constitute a resource for producing biofuel or other bioproducts that do not require extensive grinding. Dilute acid pretreatment for pine needles has been studied by Slathia et al. [7]. A continuous pyrolysis of pine needles at $500{ }^{\circ} \mathrm{C}$ was successfully proven to produce bio-oil by 
Mandal et al. [8]. However, a "green" low-temperature pretreatment method for processing them prior to hydrolysis is needed. If safe and simple enough, such a method could possibly be implemented at a local depot, prior to shipping to a biorefinery. If performed near the harvesting site, the volume of material to be transported would be reduced.

Some ecofriendly alternative solvents for pretreatment are called deep eutectic solvents (DES). DES have low volatility, non-flammability, a wide liquid range, non-toxicity, biocompatibility, and biodegradability [9]. They can be simply prepared at high purities from readily obtainable materials. In addition, DES are valuable in biofuel processing because they do not typically inactivate enzymes [10]. They are less sensitive to water content than some solvents, such as ionic liquids, which makes their use more practical with the wet biomass that is generally present at field sites [9]. They are an alternative to the most common method for the separation of cellulose and lignin in biomass, the Kraft process. The Kraft process is not particularly environmental-friendly, since it releases sulfur-containing volatile organic compounds into the atmosphere [11].

The present work investigated the pretreatment of Loblolly pine needles with different DES solvents for separation of lignin and cellulosic components of the biomass, characterizing the products. In this study, mass yield from the pretreatment was calculated and the Fourier transform infrared spectroscopy (FTIR) spectra of the two solid products from the separation analyzed. Enzymatic hydrolysis was performed to find the glucose yield from the pretreated biomass. Fiber analysis was also completed to find the composition of samples before and after pretreatment, using a National Renewable Energy Laboratory (NREL) compositional analysis procedure. High-performance liquid chromatography (HPLC) analysis of carbohydrates and insoluble lignin analysis using ultraviolet-visible (UV) spectroscopy were also used to characterize the samples. Work on DES pretreatment on pine needles, which have a structure quite different from pine wood, is not available in the literature.

\section{Materials and Methods}

\subsection{Raw Materials and Chemicals}

Loblolly pine needles were collected from the branches of 28-year-old Loblolly pine trees that had been harvested in Ruston, LA, USA, with the help of Weyerhauser, Inc., employees and then refrigerated. Fiber analysis indicated that the untreated pine needles consisted of $26.2 \%$ cellulose, $19.4 \%$ hemicellulose, $39.6 \%$ lignin, $12.0 \%$ extractives and $2.7 \%$ ash (inorganics). Choline chloride powder (BioReagent, suitable for cell culture, $\geq 98 \%$ ), formic acid (reagent grade, $\geq 95 \%$ ), acetic acid (reagent grade, $\geq 99.7 \%$ ), lactic acid solution (reagent grade, $\geq 85 \%$ ), sulfuric acid (reagent grade, 95-98, cellulase (powder) from Trichoderma reesei ATCC 26921, hemicellulase (powder) from Aspergillus niger, and cellobiase (liquid) from Aspergillus niger, were purchased from Millipore Sigma (St. Louis, MO, USA). Sodium azide, $99 \% \mathrm{~min}$, and sodium citrate dehydrate, $99.0 \% \mathrm{~min}$, were purchased from Alfa Aesar (Ward Hill, MA, USA). Denatured ethanol (90.5\%) was purchased from Duda Energy (Decatur, AL, USA). Nylon membrane discs size $0.45 \mu \mathrm{m}$ were bought from Foxx Life Sciences (Salem, NH, USA).

\subsection{Synthesis of DES}

Three types of DES solvent were prepared for pretreatment of pine needle biomass. These were chosen on the basis of their non-toxicity and likelihood for effectiveness in pretreatment [10]. The formic acid:choline chloride DES (FA:CC) was prepared by mixing the formic acid (hydrogen bond donor) and choline chloride (hydrogen bond acceptor) in the mole ratio of 2:1; lactic acid:choline chloride DES (LA:CC) was prepared by mixing lactic acid with choline chloride in the mole ratio of 10:1; and acetic acid:choline chloride (AA:CC) in the mole ratio of 2:1. After mixing the two components, mixtures of the solvents were placed in an orbital shaker at $200 \mathrm{RPM}$ at $60{ }^{\circ} \mathrm{C}$ for $20 \mathrm{~min}$, and were kept for $20 \mathrm{~min}$ more if necessary, until the solution was clear. The clear DES solvents were then stored at 
room temperature and remained transparent and liquid for several weeks until they were used. In addition, the pHs of the three DES were measured (Table 1).

Table 1. Deep eutectic solvents and their $\mathrm{pH}$ values.

\begin{tabular}{clcccc}
\hline $\begin{array}{c}\text { Hydrogen Bond } \\
\text { Donor }\end{array}$ & $\begin{array}{c}\text { Hydrogen Bond } \\
\text { Acceptor }\end{array}$ & $\begin{array}{c}\text { Molar Ratio of } \\
\text { DES }\end{array}$ & pH of DES & $\begin{array}{c}\text { pH of DES Diluted } \\
\text { 10\% with Water }\end{array}$ & $\begin{array}{c}\text { pH of DES Diluted } \\
\text { 90\% with Water }\end{array}$ \\
\hline Formic acid & Choline chloride & $2: 1$ & -0.92 & 0.70 & 1.24 \\
\hline Lactic acid & Choline chloride & $10: 1$ & -0.60 & 0.54 & 1.91 \\
\hline Acetic acid & Choline chloride & $2: 1$ & 0.47 & 1.01 & 1.84 \\
\hline
\end{tabular}

\subsection{Preparation of Biomass for Pretreatment}

Pine needles were dried at $60{ }^{\circ} \mathrm{C}$ for $24 \mathrm{~h}$, prior to milling. Milled biomass was sieved with numbers 14 and 25 mesh filters to obtain the appropriate size $(\sim 1 \mathrm{~mm}$ diameter particles) for pretreatment and stored in a closed plastic bag until use.

\subsection{Pretreatment of Pine Needles Using DES}

Dried and sieved biomass of a mass of $3 \mathrm{~g}$ was mixed with $30 \mathrm{~g}$ of each of the three types of DES: FA:CC (2:1 ratio), LA:CC (10:1 ratio), AA:CC (2:1 ratio) in separate flasks with a magnetic stirrer for continuous stirring and kept in the preheated oil bath for $1 \mathrm{~h}$ at $125^{\circ} \mathrm{C}$. Time and temperature were chosen as the minima found to be effective in prior work [12]. The flask with this solution mixture was connected to a condenser to collect liquid from the vapor of the slightly volatile DES in order to maintain the solvent volume constant. Standard errors for the results were found from triplicates of the samples that were pretreated at $125^{\circ} \mathrm{C}$ for $1 \mathrm{~h}$.

\subsection{Separation of Biomass and DES \\ 2.5.1. Filtration}

Once the pretreated biomass was cooled, biomass was separated from the DES solution using nylon membrane filters $(0.44 \mathrm{~mm})$ and a mesh filter membrane. Initially, nylon membrane filters and mesh filters were dried in a drying oven for $30 \mathrm{~min}$ and stored in a desiccator. A filtration unit was set up by connecting a Buchner funnel with a filter and a filtration flask to a vacuum pump. Pretreated biomass with the solvent was allowed to pass through the mesh filter; filter cake (filtride) from the filtration was rinsed with $25 \mathrm{~mL}$ of ethyl alcohol to wash away any remaining DES on the residues by magnetically stirring for $20 \mathrm{~min}$ and filtering with the same mesh filter.

The filtride (biomass) from the above filtration was rinsed with $75 \mathrm{~mL}$ of deionized water by magnetically stirring at $50{ }^{\circ} \mathrm{C}$ for $20 \mathrm{~min}$. Rinsing with deionized water was undertaken three times to remove DES left on the biomass. Finally, rinsing with deionized water was repeated for another $24 \mathrm{~h}$ at $50{ }^{\circ} \mathrm{C}$ to obtain biomass without any DES. A $0.44 \mathrm{~mm}$ nylon filter was used to separate the rinsed biomass with deionized water using a vacuum pump. Filtered biomass was dried at $105^{\circ} \mathrm{C}$ for $24 \mathrm{~h}$ prior to weighing, to ensure all moisture was removed.

\subsubsection{Lignin Precipitation}

Filtrate from the vacuum filtration, which was expected to have lignin, DES, and ethyl alcohol was collected into a flask, then $175 \mathrm{~mL}$ of deionized water was added to precipitate lignin and separate it from DES, ethyl alcohol and deionized water. Precipitated biomass was separated using a nylon membrane filter and a vacuum pump. After separation, precipitate was dried at $105^{\circ} \mathrm{C}$ for $24 \mathrm{~h}$ prior to weighing. All the procedures were repeated three times to get triplicates to provide details on measurement error. 


\subsection{Fourier Transform Infrared Spectroscopy (FTIR)}

A Mattson Genesis II FTIR (Mattson Technology, Fremont, CA, USA) was used to obtain the spectra of pretreated biomass samples. This third-generation infrared spectrometer has a high signal-to-noise ratio, high accuracy for wave numbers, and an error range less than $0.01 \mathrm{~cm}^{-1}$. As the standard method to prepare solid samples for FTIR spectrometry is to use $\mathrm{KBr}$ pellets, $1 \mathrm{mg}$ of sample was mixed with $100 \mathrm{mg}$ of $\mathrm{KBr}$ and a pellet was made with a pellet holder press by applying pressure. Single beam spectra of the samples were collected by running 32 scans with resolution $2 \mathrm{~cm}^{-1}$ from wave number 3000 to $800 \mathrm{~cm}^{-1}$. FTIR analysis was performed on both the raw biomass, pretreated biomass, and precipitated biomass. Data analysis of obtained spectra was performed using OMNIC software to allow accessing the spectra and calculating peak areas. Table 2 shows the vibrations specifically used to evaluate cellulose and lignin content of the samples. Cellulose vibrations used were $1160 \mathrm{~cm}^{-1}$ and $1425 \mathrm{~cm}^{-1}$ for type I/type II amorphous stretching and crystalline cellulose, respectively. The lignin vibration used was at $1515 \mathrm{~cm}^{-1}$.

Table 2. Wavenumber vibration assignments and references.

\begin{tabular}{ccc}
\hline Wavenumber $\left(\mathbf{c m}^{-\mathbf{1}}\right)$ & Band Assignment & Reference \\
\hline $\mathbf{1 1 6 0}$ & $\begin{array}{c}\text { Amorphous stretching of cellulose } \\
\text { type I and type II }\end{array}$ & (Shi and Li, 2012) [13] \\
\hline $\mathbf{1 4 2 5}$ & Crystalline cellulose & (Raj et al., 2015) [14] \\
\hline $\mathbf{1 5 1 5}$ & Lignin aromatic ring skeletal sketch & (Raj et al., 2015) [14] \\
\hline
\end{tabular}

\subsection{Enzymatic Hydrolysis}

NREL's enzymatic saccharification of the lignocellulosic biomass LAP 009 protocol was followed to understand the saccharification of cellulose from pretreated biomass in order to determine the maximum digestibility possible [15]. Biomass after pretreatment was dried at $105^{\circ} \mathrm{C}$ in a drying oven for $24 \mathrm{~h}$. A sample of $0.1 \mathrm{~g}$ of ground biomass was mixed with $5 \mathrm{~mL}$ of sodium citrate buffer of $\mathrm{pH} 5.05$, and $100 \mu \mathrm{L}$ of $2 \%$ sodium azide solution. The total volume was brought to $10 \mathrm{~mL}$ by adding an appropriate amount of deionized water as described in the NREL protocol. Subsequently, cellulase, hemicellulase, and cellobiase were added at a concentration of 5, 14 and 50 units per $0.1 \mathrm{~g}$ of sample, respectively. The mixture of biomass, buffer, sodium azide, and enzyme cocktail was placed in the orbital shaker set at $200 \mathrm{RPM}$ at $50{ }^{\circ} \mathrm{C}$. As per the NREL protocol, samples were collected at $24 \mathrm{~h}, 48 \mathrm{~h}$, and $72 \mathrm{~h}$ prior to filtering through a $0.45 \mu \mathrm{m}$ syringe filter and stored in the refrigerator at $4{ }^{\circ} \mathrm{C}$ prior to HPLC analysis. Glucose yield is calculated as a fraction of cellulose present in biomass that was recovered as glucose. The glucose yield was obtained using Equation (1).

$\%$ glucose yield $=\frac{0.9 * 10 \mathrm{~mL} \text { volume hydrolysis } * \text { glucose concentration } \frac{g}{\mathrm{~mL}} \text { (corrected with blanks) }}{g \text { pretreated substrate } * \text { fraction cellulose in pine } * \text { mass yield pretreatment }}$

The correction factor that accounts for the conversion from the biopolymer cellulose to the monomer glucose is 0.9 .

\subsection{Carbohydrate Analysis Using High-Performance Liquid Chromatography (HPLC)}

The cellulose, hemicellulose, and lignin content of all the raw and pretreated samples were determined by quantitative saccharification with acid hydrolysis and subsequent HPLC analysis, using NREL protocols LAP/TP-510-426 18 through 22 [16]. For raw biomass, ethanol extraction was carried out to remove the non-structural components of the biomass prior to acid hydrolysis and thus the biomass fraction regarded as extractives was removed from the raw biomass. For pretreated samples, the extractives component was assumed to have been removed during the pretreatment process, so that these samples directly progressed to acid hydrolysis for compositional analysis. 
The concentrations of glucose, xylose, arabinose, galactose, and mannose were quantified using an HPLC (ThermoFisher Scientific, Waltham, MA, USA) equipped with refractive index detector and an Aminex HPX-87P column $300 \times 7.8 \mathrm{~mm}$, (Bio-Rad Laboratories, Inc., Hercules, CA, USA). The column temperature was maintained at $80^{\circ} \mathrm{C}$ and the flow rate was $0.6 \mathrm{~mL} \mathrm{~min}{ }^{-1}$ (DI water). Each experiment was performed in triplicate. Total cellulose release upon acid hydrolysis was determined as the sum of cellobiose and glucose and the total hemicellulose release was determined as the sum of xylose, galactose, arabinose, and mannose. The sum of acid insoluble and acid soluble lignin was represented as total lignin content available in each sample.

\subsection{Acid Soluble Lignin Analysis}

The NREL fiber analysis procedure was followed to measure acid soluble lignin from the biomass after acid hydrolysis [16]. A UV-2401PC spectrophotometer (Shimadzu Corporation, Kyoto, Japan) was used to analyze acid soluble lignin in the biomass. Once the biomass was pretreated it was hydrolyzed with $70 \% \mathrm{H}_{2} \mathrm{SO}_{4}$ and, with the hydrolysis, lignin in the sample was dissolved. Subsequently, $3000 \mu \mathrm{L}$ of this sample was measured and diluted 10 times with deionized water. With deionized water as a blank, analytes (lignin) in the sample were measured by absorbance at a wavelength of $260 \mathrm{~nm}$.

\subsection{Soxhlet Extraction}

Non-structural materials from the biomass must be removed from the biomass prior to compositional analysis to prevent any obstructions in later analytical procedures. Water soluble and ethanol soluble extractives in the biomass were removed by Soxhlet extraction. Biomass of weight $3 \mathrm{~g}$ was placed in a thimble and $200 \mathrm{~mL}$ of ethyl alcohol transferred into a conical flask. The thimble with biomass was inserted carefully into a Soxhlet siphon tube and kept above the conical flask with ethyl alcohol. The whole setup was kept in an oil bath at $80^{\circ} \mathrm{C}$ for $24 \mathrm{~h}$, and after $24 \mathrm{~h}$ biomass from the thimble was taken out and the loss of biomass measured. The percentage of extractives removed was then calculated.

\section{Results and Discussion}

\subsection{Mass Yield from Deep Eutectic Solvents (DES) Pretreatment}

When Loblolly pine needles were treated with the DES acetic acid:choline chloride 3:1 molar ratio (AA:CC), the percentage of mass yield for the biomass was $61.25 \%$, with a standard error of $2.63 \%$. This mass yield was high when compared to the biomass yields for pretreatment with lactic acid:choline chloride 10:1 molar ratio (LA:CC) and formic acid:choline chloride 2:1 molar ratio (FA:CC) (Figure 1). Average mass yield with LA:CC was lower than FA:CC at $49.55 \%$, however the standard error for LA:CC was $8.32 \%$, so no difference can be confirmed. Mass yield for FA:CC was low because more of the solids were solubilized, leading to a higher mass of the precipitate from the filtrate. Heat required was $0.31 \mathrm{~kW}-\mathrm{h}$ for the pretreatment process, which is relatively low as more energy can be produced with resultant glucose concentration [17].

When the biomass was treated with glycerol as a control, no reaction was observed and the biomass remained the same as raw biomass. This result made it clear that the heat treatment alone $\left(1 \mathrm{~h}\right.$ at $\left.125^{\circ} \mathrm{C}\right)$ had no effects on biomass, unlike the pretreatment with DES. Extractives in the biomass were removed using the Soxhlet extraction procedure from NREL and were found to be about $26.10 \%$ of raw biomass.

After the separation of biomass filtrate was precipitated by the addition of deionized water, the mass of precipitated biomass (lignin precipitate) was higher when the biomass was treated with FA:CC, at $31.56 \%$ with a standard error of $1.75 \%$. It was $20 \%$ with a standard error of $2.87 \%$ in the case of LA:CC and $17.51 \%$ with a standard error of $0.76 \%$ with AA:CC. Thus, larger amounts of lignin can be separated from the biomass when it is pretreated with FA:CC and LA:CC compared to AA: CC. A visual inspection of the pine needles treated with FA:CC and LA:CC appeared to show a greater extent of biomass 
breakdown compared to AA:CC. FA:CC pretreatment may be more effective because it has a lower $\mathrm{pKa}$ value than the other DES [12].

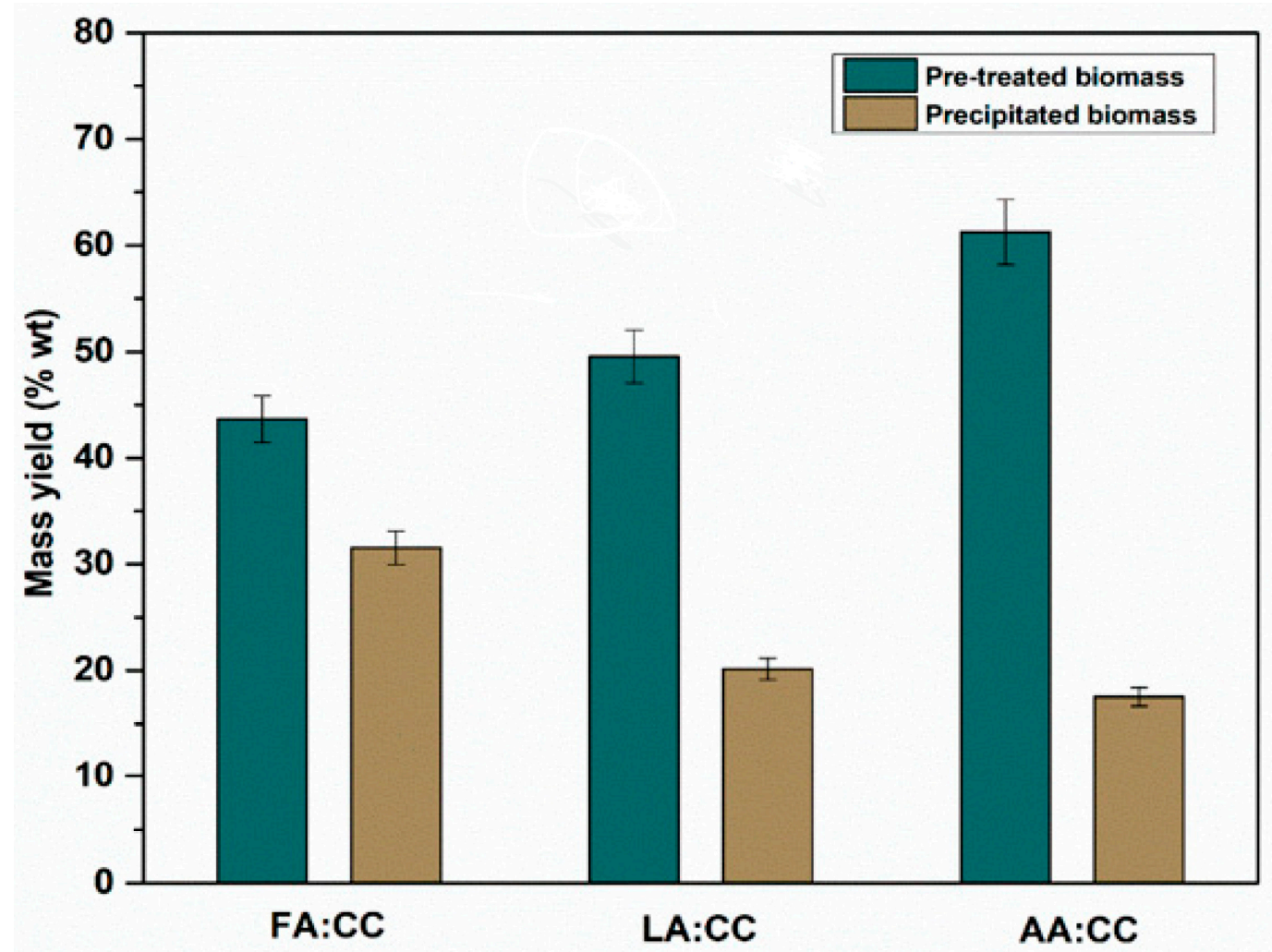

Figure 1. Mass yield and precipitated biomass with 3 types of deep eutectic solvent (DES).

3.2. Fourier Transform Infrared (FTIR) Analysis of Pretreated Loblolly Pine Needles and Precipitate from Deionized Water

FTIR analysis of raw and pretreated biomass elucidated the transformation in biomass composition and structure in the process of DES pretreatment. FTIR spectra of raw and pretreated biomass are shown in Figure S1. The resulting spectra show more pronounced vibrations for the pretreated samples at $1425 \mathrm{~cm}^{-1}$ (native type 1 cellulose) and $1160 \mathrm{~cm}^{-1}$ (amorphous stretching of cellulose type I and type II) indicating the pretreated biomass contained considerable amounts of crystalline and disordered cellulose (Figure S1). These findings suggest that the structure of the pretreated biomass was altered, possibly leading to improved enzymatic saccharification. The intensity of the vibration at $1515 \mathrm{~cm}^{-1}$, from the lignin aromatic ring skeletal stretch, appears to have decreased somewhat, suggesting that some lignin may have been removed.

\subsection{Enzymatic Hydrolysis}

To evaluate the efficiency of the DES pretreatment to enhance the cellulose accessibility to hydrolytic enzymes, the rates of conversion of cellulose into glucose during enzymatic hydrolysis of raw and pretreated biomass were measured. The glucose yields (the ratio of glucose liberated by enzymatic hydrolysis to glucose that exists as cellulose in the raw or pretreated biomass) as a function of hydrolysis time for pine needles are shown in Figure 2. 


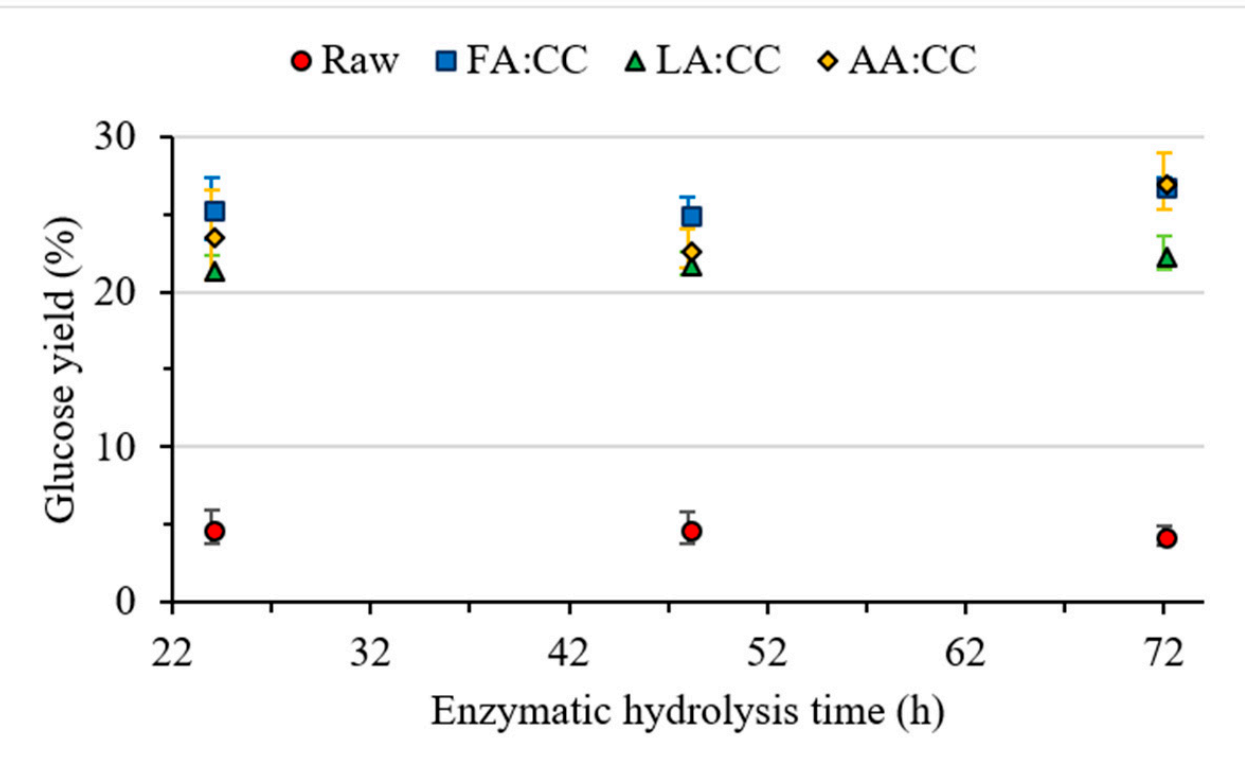

Figure 2. Glucose yield of Loblolly pine needles untreated and pretreated with 3 types of DES at $125^{\circ} \mathrm{C}$ for $1 \mathrm{~h}$. Standard error bars are shown.

Glucose yield versus enzymatic hydrolysis time is shown in Figure 2, for samples after pretreatment in various DES for $1 \mathrm{~h}$ at $125^{\circ} \mathrm{C}$, as well as for raw biomass. Little difference can be seen among the glucose yields from the samples pretreated with different DES, but a low concentration of glucose was liberated for the pine needles that did not undergo any DES pretreatment. This result indicates the necessity of pretreatment preceding enzymatic hydrolysis to change some structural characteristics of pine needles and to increase cellulose accessibility to hydrolytic enzymes in order to provide high sugar yield, due to the recalcitrant lignocellulosic structure of the biomass. Time of hydrolysis did not make a substantial difference in glucose yield, suggesting that a short hydrolysis time would suffice or possibly that a lower concentration of enzyme could have been used. The glucose yield for the LA:CC pretreatment was slightly lower than those for the other pretreatments. The chromatograms from HPLC analysis of the sugars from enzymatic hydrolysis (Figure 3) illustrates the increased sugar concentration in the pretreated biomass.

An enzymatic hydrolysis time of $24 \mathrm{~h}$ was investigated by Oh et al. (2020) for similar DES used in pretreatment of pine wood powder [18]. In this study, LA:CC and FA:CC were found to be quite effective in releasing sugars, but AA:CC to be less so. Differences between the types of biomass structures may account for the ineffectiveness of AA:CC for pretreatment of powdered wood. Oh et al. (2020) reported slightly lower $\beta$ basicity solvatochromic parameters for the more effective DES, which may also influence their usefulness [18].

\subsection{Fiber Analysis}

Figure 4 shows the results for fiber analysis for raw and DES pretreated pine needles. In each case, a higher proportion of cellulose exists in the pretreated biomass than in the raw. The ratio of cellulose to lignin for the pretreated biomass is greater than or equal to that for the raw biomass. Lignin tends to impede enzymatic hydrolysis of biomass, both by blocking enzyme access to cellulose and by inhibiting the enzyme [19]. Thus, the pretreated biomass with a higher cellulose content should be more suitable for obtaining sugar from the enzymatic hydrolysis process, as indeed was seen in the previous sections' results. A lower proportion of hemicellulose (comprising for untreated pine needles $21 \%$ xylose, $62 \%$ galactose, $0 \%$ arabinose, and $17 \%$ mannose) was found in the DES pretreated biomass. This effect can be seen in the smaller amounts of xylose in the enzymatic hydrolysis liquid from DES pretreated biomass, as shown in Figure 3. All extractives were 
removed by the pretreatment, and their impeding of hydrolysis may have a minor effect on sugars produced.

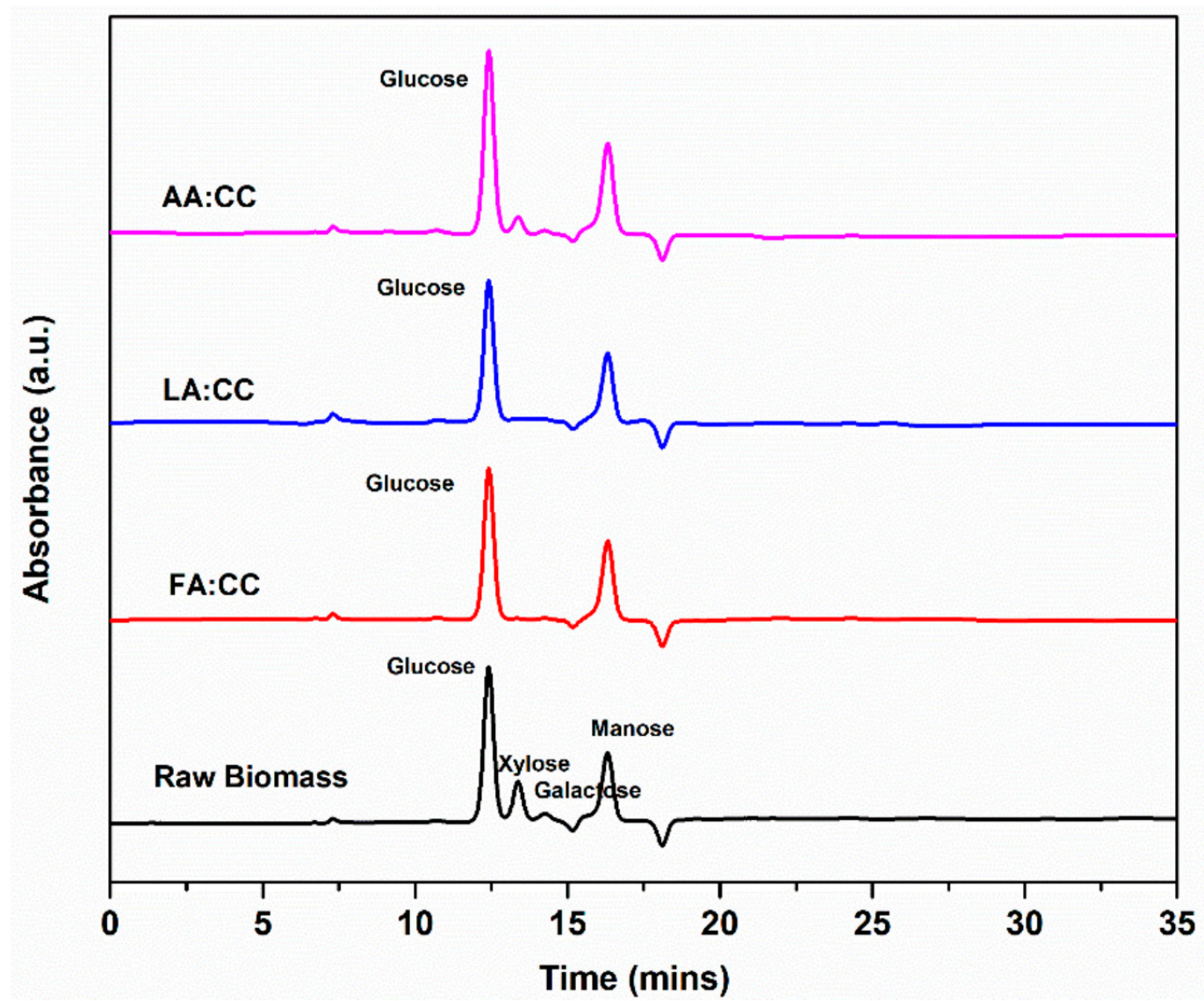

Figure 3. Chromatograph of enzymatic hydrolysis liquid.

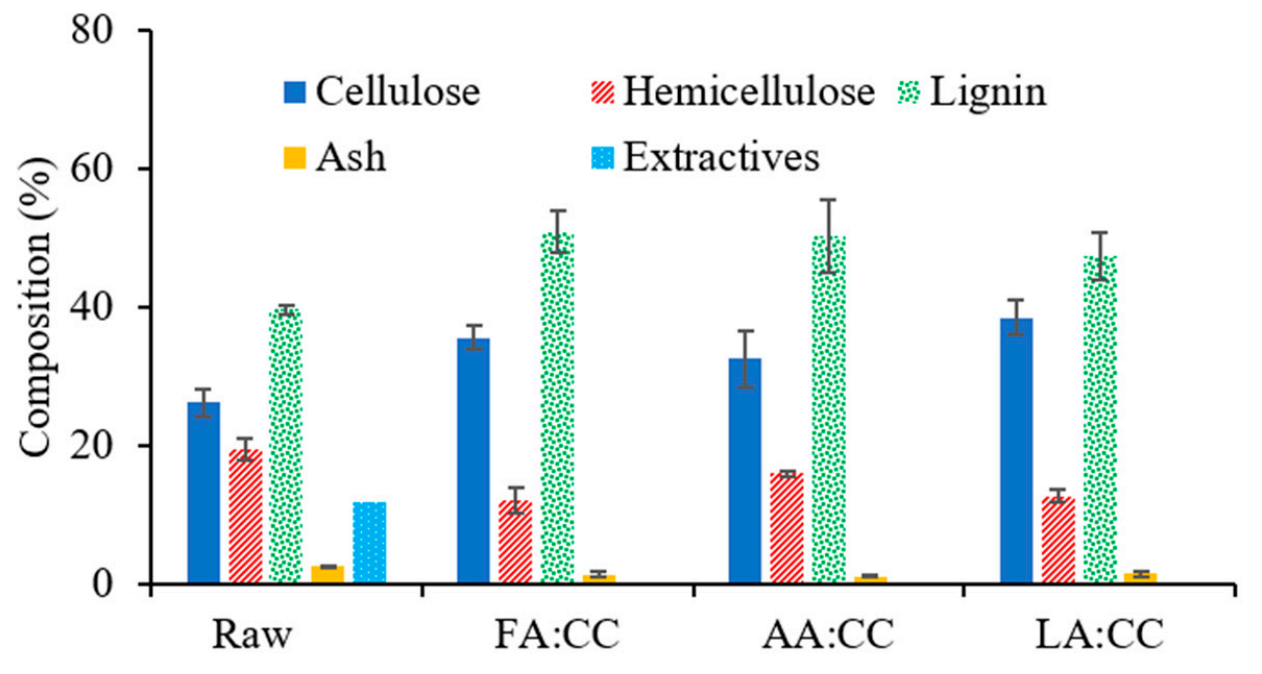

Figure 4. Composition of pine needles and pretreated pine needles from fiber analysis. 
In addition, the pretreated biomass has less ash (inorganics) compared to the raw pine needles. These findings suggest that in addition to removal of extractives, the lignocellulosic structure was disrupted, with a portion of the lignin and hemicellulose no longer shielding the cellulose in the biomass. For rice husks, beech wood, loblolly pine, tree heather, and gum rockrose, other researchers have reported lignin removal with DES pretreatment $[10,20-22]$. Lignin has also been reported to be effectively removed from maritime pine wood sawdust and pine wood powder [18,23]. However, the wood particles in sawdust are very different in structure compared to pine needles. Data on pine needle DES pretreatment is not available in the literature, making the present study unique.

\section{Conclusions}

Despite its recalcitrance, pine needle biomass had the potential to act as a substrate for pretreatment with DES. From the mass yields and fiber analysis results obtained it was clear that the extractives and some portion of the lignin, hemicellulose, and ash were removed from the samples with DES pretreatment. Enzymatic hydrolysis data showed that DES pretreatment enhanced the glucose yields significantly after enzymatic saccharification compared to the untreated pine needles. FTIR analysis of DES-pretreated biomass samples suggested that the enhanced glucose yield was due to removal of lignin and disruption of the biomass structure during pretreatment, so that the pretreated biomass was rich in cellulosic content. Based on the results shown in this study, among the three types of DES, FA:CC and AA:CC pre-treatment had better potential for biomass pretreatment compared to LA:CC.

Supplementary Materials: The following are available online at https://www.mdpi.com/article/ 10.3390/biomass1010001/s1, Figure S1: FTIR transmission spectra of raw and FA:CC, LA:CC and AA:CC pretreated biomass.

Author Contributions: Conceptualization, J.G.L.; methodology, J.G.L. and P.G.; formal analysis P.G. and N.K.; investigation, P.G. and N.K.; resources, J.G.L.; data curation, P.G., J.G.L. and N.K.; writingoriginal draft preparation, P.G.; writing—review and editing, P.G., J.G.L. and N.K.; visualization, P.G. and N.K.; supervision, J.G.L.; project administration, J.G.L.; funding acquisition, J.G.L. All authors have read and agreed to the published version of the manuscript.

Funding: The authors want to sincerely acknowledge the Region 6 U.S. Environmental Protection Agency P2 grants [Grant numbers NP-01F55301-0 and 01F86601] for support of this project.

Data Availability Statement: Data are available from the corresponding author.

Acknowledgments: The authors acknowledge the help of Jalia Payne, Landry Tucker, and Sven Eklund of Louisiana Tech University.

Conflicts of Interest: The authors declare no conflict of interest.

\section{References}

1. Malaeke, H.; Housaindokht, M.R.; Monhemi, H.; Izadyar, M. Deep eutectic solvent as an efficient molecular liquid for lignin solubilization and wood delignification. J. Mol. Liq. 2018, 263, 193-199. [CrossRef]

2. Lee, J. Biological conversion of lignocellulosic biomass to ethanol. J. Biotechnol. 1997, 56, 1-24. [CrossRef]

3. Panwar, N.L.; Kaushik, S.C.; Kothari, S. Role of renewable energy sources in environmental protection: A review. Renew. Sustain. Energy Rev. 2011, 15, 1513-1524. [CrossRef]

4. Figueiredo, P.; Lintinen, K.; Hirvonen, J.T.; Kostiainen, M.A.; Santos, H.A. Properties and chemical modifications of lignin: Towards lignin-based nanomaterials for biomedical applications. Prog. Mater. Sci. 2018, 93, 233-269. [CrossRef]

5. Nix, S. Loblolly Pine, an Important Tree in North America. Available online: https://www.thoughtco.com/loblolly-pineimportant-tree-north-america-1342788 (accessed on 23 November 2020).

6. Lange, B.M.; Catherine, L.; Heinrich Sandermann, J. Elicitor-Induced Spruce Stress Lignin: Structural Similarity to Early Developmental Lignins. Plant Physiol. 1995, 108, 1277-1287. [CrossRef]

7. Slathia, P.S.; Raina, N.; Kiran, A.; Kour, R.; Bhagat, D.; Sharma, P. Dilute acid pretreatment of pine needles of Pinus roxburghii by response surface methodology for bioethanol production by separate hydrolysis and fermentation. Biomass Convers. Biorefinery 2020, 10, 95-106. [CrossRef] 
8. Mandal, S.; Bhattacharya, T.K.; Haydary, J.; Husar, J.; Tanna, H.R.; Haz, A. Valorization of Pine Needles by Thermal Conversion to Solid, Liquid and Gaseous Fuels in a Screw Reactor. Waste Biomass Valorization 2019, 10, 3587-3599. [CrossRef]

9. Francisco, M.; van den Bruinhorst, A.; Kroon, M.C. New natural and renewable low transition temperature mixtures (LTTMs): Screening as solvents for lignocellulosic biomass processing. Green Chem. 2012, 14, 2153-2157. [CrossRef]

10. Lynam, J.G.; Kumar, N.; Wong, M.J. Deep eutectic solvents' ability to solubilize lignin, cellulose, and hemicellulose; thermal stability; and density. Bioresour. Technol. 2017, 238, 684-689. [CrossRef]

11. Catalan, L.J.J.; Liang, V.; Jia, C.Q.; Walton, C. Effects of process changes on concentrations of individual malodorous sulphur compounds in ambient air near a Kraft pulp plant in Thunder Bay, Ontario, Canada. Wit Trans. Ecol. Environ. 2007, 101, 437-447. [CrossRef]

12. Kumar, N.; Gautam, R.; Stallings, J.D.; Coty, G.G.; Lynam, J.G. Secondary Agriculture Residues Pretreatment Using Deep Eutectic Solvents. Waste Biomass Valorization 2020, 12, 2259-2269. [CrossRef]

13. Shi, J.T.; Li, J. Metabolites and chemical group changes in the wood-forming tissue of pinus koraiensisunder inclided conditions. Bioresources 2012, 7, 3463-3475.

14. Raj, T.; Kapoor, M.; Gaur, R.; Christopher, J.; Lamba, B.; Tuli, D.K.; Kumar, R. Physical and Chemical Characterization of Various Indian Agriculture Residues for Biofuels Production. Energy Fuels 2015, 29, 3111-3118. [CrossRef]

15. Selig, M.W.N.; Ji, Y. Enzymatic Saccharification of Lignocellulosic Biomass, LAP-009 NREL Analytical Procedure; Technical Report NREL/TP-510-42629; National Renewable Energy Laboratory (NREL): Golden, CO, USA, 2008.

16. Sluiter, A.; Hames, B.; Ruiz, R.; Scarlata, C.; Sluiter, J.; Templeton, D.; Crocker, D. Determination of structural carbohydrates and lignin in biomass. Lab. Anal. Proced. 2008, 1617, 1-16.

17. Kumar, N.; Muley, P.D.; Boldor, D.; Coty, I.V.G.G.; Lynam, J.G. Pretreatment of waste biomass in deep eutectic solvents: Conductive heating versus microwave heating. Ind. Crop. Prod. 2019, 142, 111865. [CrossRef]

18. Oh, Y.; Park, S.; Jung, D.; Oh, K.K.; Lee, S.H. Effect of hydrogen bond donor on the choline chloride-based deep eutectic solvent-mediated extraction of lignin from pine wood. Int. J. Biol. Macromol. 2020, 165, 187-197. [CrossRef]

19. Brandt, A.; Gräsvik, J.; Hallett, J.P.; Welton, T. Deconstruction of lignocellulosic biomass with ionic liquids. Green Chem. 2013, 15, 550-583. [CrossRef]

20. Okur, M.; Eslek Koyuncu, D.D. Investigation of pretreatment parameters in the delignification of paddy husks with deep eutectic solvents. Biomass Bioenergy 2020, 142, 105811. [CrossRef]

21. Mamilla, J.L.K.; Novak, U.; Grilc, M.; Likozar, B. Natural deep eutectic solvents (DES) for fractionation of waste lignocellulosic biomass and its cascade conversion to value-added bio-based chemicals. Biomass Bioenergy 2019, 120, 417-425. [CrossRef]

22. Carrión-Prieto, P.; Hernández-Navarro, S.; Sánchez-Sastre, L.F.; Marcos-Robles, J.L.; Martín-Gil, J.; Martín-Ramos, P. Furfural, 5-HMF, acid-soluble lignin and sugar contents in C. ladanifer and E. arborea lignocellulosic biomass hydrolysates obtained from microwave-assisted treatments in different solvents. Biomass Bioenergy 2018, 119, 135-143. [CrossRef]

23. Fernandes, C.; Melro, E.; Magalhães, S.; Alves, L.; Craveiro, R.; Filipe, A.; Valente, A.J.M.; Martins, G.; Antunes, F.E.; Romano, A.; et al. New deep eutectic solvent assisted extraction of highly pure lignin from maritime pine sawdust (Pinus pinaster Ait.). Int. J. Biol. Macromol. 2021, 177, 294-305. [CrossRef] [PubMed] 